\title{
Identifying the Influence of Design Variations on the Performance of PV Systems for Net-Plus Energy Residential Buildings in Egypt
}

\author{
Hussein Hamza ${ }^{1}$, Mohamed Ayman Ashour ${ }^{2}$, Hanan Sabry ${ }^{3}$ and Mostafa Refat Ismail ${ }^{4}$ \\ 1,2,3,4 Faculty of Engineering, Ain Shams University, 1 Elsarayat St., Abbaseya, 11517 Cairo, Egypt \\ ${ }^{1}$ ORCID: 0000-0002-4355-018X, ${ }^{3}$ ORCID: 0000-0003-2597-9553, ${ }^{4}$ ORCID: 0000-0003-1960-9193
}

\begin{abstract}
Net-zero and net-plus energy residential prototypes are becoming high prioritized due to the significant impact the buildings imply on the energy consumption and the environment. Although some previous studies investigated the influence of design variations for different parameters on the performance of a PV system, yet most of these studies did not focus on geometric parameters and how can they contribute in the overall performance of the system. This study proposes a methodology to investigate how the impact of design variations of a pre-defined set of parameters for a PV system on the total energy generated can be estimated through a few number of experiments. This study focused mainly on four parameters; the type of the PV technology used and three geometric parameters including; area, tilt angle and azimuth. The main effects and interactions between these parameters were computed using matrix algebra and Multiple linear regression. A representative case study in Cairo, Egypt is presented as an implementation of the proposed methodology to deduce a prediction model from a $2^{4-1}$ fractional factorial, and the outcome of this model is validated. Results show that good estimates of most of these parameters are obtained, where aliasing was only limited to the two-factor interactions, which is an acceptable trade-off.
\end{abstract}

Keywords: Photovoltaics; Multiple Linear Regression; Factorial Design, NZEB, Building performance Simulation

\section{INTRODUCTION}

\subsection{Research Background}

The topic of zero energy buildings has been recently brought to a great attention due to the significant impact of the buildings on the energy consumption and the environment. In the United States, for example, according to the annual energy review by the Energy Information Administration (EIA) in 2005; both the commercial and residential sector almost consumed $40 \%$ of the primary energy and approximately $70 \%$ of the electricity [1]. In the European Union, the demand for energy in the building sector represents around $40 \%$ of the final energy consumption [2]. In Egypt, the demand for the electricity consumption is dominated by the residential use. The main source of electricity generation is from (combined cycle) gas and steam, whereas the current contribution for both wind and solar energy is only around 1 percent or less [3]. Egypt is working to grow its installed capacity of renewable energy; targeting to develop 10 GW from wind and solar projects by the year 2022 [4]. With the recent shortages in fuel, the rising electricity costs and growing demand for energy, net zero and net plus energy residential prototypes are becoming high prioritized.

Net-Zero and Net-Plus Energy Buildings (NZEBs \& NPEBs) are thus emerging as a quantifiable design concept and a promising solution to minimize the impact of buildings on the environment, and these concepts have become part of the energy policy in several countries. In the recast of the EU's Energy Performance of Buildings Directive (EPBD); it is specified that by the end of 2020; all new buildings shall be "nearly zero energy buildings". The Building Technologies Program of the US Department of Energy (DOE) set a strategic goal to achieve "marketable zero energy homes by 2020 and commercial zero energy buildings by 2025 " [5]. In a similar direction, improving its regulatory framework, Egypt has made a great progress under the "Grid Access" and Independent Power producers (IPP)s factors. In 2014, Egypt adopted a grid code for wind parks and small-scale PV projects, and is currently preparing the grid code for medium and largescale PV [6]. The aim of this study, however; is to propose a methodology to investigate the impact of design variations for a pre-defined set of parameters on the overall performance of a photovoltaic system in net-plus energy residential prototyping. A representative case study in Cairo, Egypt is presented as an implementation of this proposed methodology.

\subsection{Literature review}

Previous studies were conducted to investigate different geometric design parameters for photovoltaic systems, yet most of these studies did not interpret how the integration of these parameters and their interactions with each other can significantly impact the overall performance of the system as a whole. The magnitudes of these variables and their interaction are highly important from the architectural perspective. Some studies, however; tried to figure out the contribution of some configurations and components of PV systems using some statistical methods; yet most of these studies did not address the contribution of geometric factors (such as area, tilt angle and orientation) on the overall performance of the system. This is illustrated in this literature review for the next two paragraphs.

Many previous studies investigated the optimum tilt angle " $\beta$ " and the surface azimuth " $\gamma$ " of PV systems in different locations around the world. Dhimish and Silvestre [7] demonstrated the impact of the azimuth angle variations on the annual energy production of PV installations located in Huddersfield, UK. Yan, et al. [8] proposed a theoretical model to estimate the performance of PV systems with various tilt angles and orientations in Brisbane, Australia. Ismail, et al. [9] tried to optimize the tilt angle a hybrid power system from 
photovoltaic and micro-turbine to maximize the annual energy production at Palestine. Jafarkazemi and Saadabadi [10] tried to optimize both the tilt angle and azimuth of solar cells panels in Abu Dhabi, United Arab Emirates (UAE). Bakirci [11] tried to obtain the optimum tilt angles for the solar panels from solar radiation data monitored in Turkey. Asowata, et al. [12] determined the optimum tilt angles for photovoltaics for winters at Vaal Triangle, South Africa. Wada, et al. [13] proved that the tilt angle for PV array maximum annual energy is different than that to achieve the maximum annual irradiation. Chang [14] optimized the tilt angles of south facing PV modules to obtain the maximum output electrical energy in Taiwan using a particle-swarm optimization method. Hussein, et al. [15] determined the optimum tilt angle at Cairo, Egypt. These previous studies, together with many similar studies (refer to [16] for other relevant studies) help to reliably choose optimum tilt angles and orientation for PV planning system. These studies, however; did not describe the trade-off between these different parameters; how they interact with each other, and how this interaction influences the whole system. To improve our understanding of such systems, these potential influences should be considered; to identify how design variations for these parameters can significantly affect the total energy generated.

Some previous studies used statistical approaches for similar purposes. Le and Benjapolakul [17] evaluated the lifetime energy yield the rooftop PV systems from many high-volume installed PV systems countries and regions based on machine learning techniques. The study applied bootstrap technique to find out if any significant difference in energy yield caused by the inverter brands as well as PV inverter configurations. Two configurations were considered; micro-inverter and string inverter. Multiple Linear Regression (MLR) was used to calculate the contribution, of PV system configuration and components to the PV energy yield. The study was limited to the four factors; the number of solar panels, the rated power of panel, the number of inverters and the inverter power. Mouatasim and Darmane [18] analyzed a PV system with three different technologies; polycrystalline, amorphous, and monocrystalline. Simple linear regression (SLR) was used to estimate the influence of the output PV power at specific time of the day over the output power cumulated in the whole day. MLR was also used to estimate the influence of three factors; inclined solar irradiance, horizontal solar irradiance and temperature over the cumulated output power. Malvoni, et al. [19] used data monitored over 43 months to investigate the performance of a PV system located in Italy. Linear regression and Classical Seasonal Decomposition (CSD) methods were used to estimate the degradation rate of the PV system. Di Piazza and Vitale [20] proposed a simplified method based on the experimental measurement to deduce maximum power point voltage and current values, from the data to identify the PV model parameters on the basis of defined intervals of solar irradiance and temperature using a least squares regression. Di Piazza, et al. [21] proposed an approach for PV sources modeling based on the identification of solar irradiance, cell temperature and voltage and currents at maximum power points for a given PV array using robust least squares linear regression methods. Liu, et al. [22] used SLR and MLR methods to analyze the influence of irradiance, air temperature and wind velocity on power generation amount and module conversion efficiency of PV system in Kitakyushu science and research park in japan based on recoded data in 2002.

Although the aforementioned literature has investigated the influence of some design factors on the performance of a PV system, yet most of these studies did not focus on geometric variables. They did not address the contribution of each of the geometric factors such as "Area", "Tilt Angle" and "Orientation" on the overall performance of the system. From an architectural point of view, these variables are important to take building design decision. When a proposed design for a building is expected to meet a specific performance target (such as net-zero or net-plus energy level), it is then important to understand the potential for such design variations to cause differences on the overall performance. This study proposes a methodology for estimating the impact of design variations for these variables on the performance of photovoltaic systems in net-plus energy residential buildings.

\section{METHOD}

In this study, a proposed methodology to investigate the impact of design variations for a pre-defined set of parameters on the performance of a photovoltaic system is presented. This involves performing a set of factorial experimentation where a fixed number of levels is selected for each factor to run the experiments in all possible combinations. Only one level of scalar response (total energy generated), and two-level data for the dependent parameters (low and high levels) are considered. This methodology helps to understand and identify how such variations for a photovoltaic system can significantly affect the total energy generated of an NPEB. This study focused mainly on four variables; one categorical parameter, which is the type of the PV technology used, and three geometric parameters including; area, tilt angle and azimuth. However; this approach could easily be extended to other dimensions; including more variables and more levels of response.

To conduct these experiments; recorded data obtained from a Data Acquisition System (DAS) monitoring real installed PV systems shall be used to get accurate predictions. However, in this study; building performance simulation using the IES -VE software is rather used. The factors' main effects as well as mutual interactions among these factors are computed by Multiple linear regression using least square method to build a predictive model. "R computer software" was used for this purpose. This proposed method is implemented on a representative case study for a PV system located in Cairo, Egypt. In section 3, the experimental approach adopted in this study is discussed. This includes; two level full-factorial, fractional-factorial design of experiments, and multiple linear regression analysis using least squares model. Planning for the experiments is discussed in section 4. In this section; the resolution of the fractional-factorial is decided. Also the ranges of the variables are assigned in order to achieve the objectives of the experiments in the simplest possible way. In section 5, A representative case study as an implementation of the proposed methodology is presented and the outcome is validated. 
Results, discussion and further research work are presented in section 6 .

\section{EXPERIMENTAL APPROACH}

In order to learn more about a system, it needs to be excited; a change for one or more factors should intentionally be caused. When these changes are made, one could say that an experiment has been run. Every experiment has these two components; (1) an outcome, and (2) One or more factors. An outcome (or the response) is the result of an experiment whereas the factors (also called variables) are the things changed in order to influence this outcome. Using a set of structured experiments, a decision about whether a given factor is having a significant impact on a response variable can be made. The key point is this to cause this change, and then observe the system. Experimental designs are thus specific procedures that tells how to these factors could be assigned to get the most information out of the experimental data [23].

However; All experiments must have at least one factor that is changed. These factors could either be quantitative factors called "numeric factors" - or qualitative factors - called "categorical factors". An example of numeric factors could be two different temperatures or two different angles, whereas categorical factors might include two types of materials (A or B). Another important difference is that in numeric variables; there is some order (e.g. an area of $15 \mathrm{~m}^{2}$ is less than $30 \mathrm{~m}^{2}$, and so on), whereas, on the contrary, categorical variables have no implicit ordering (e.g. the names for types A and B may be arbitrary changed around). However; most experiments will have both numeric and categorical factors [24].

\subsection{Factorial Design of Experiments}

The simplest type of experiments could involve only an outcome variable, $y$, and one input variable, $x$. However; it is common that experiments might involve two or more factors that affect the response variable. In his work on experimental design; Fisher argued that one-factor-a-time experimentation approach was insufficient to determine the individual and mutual effects of these factors on the outcome, since the response to one treatment might be conditioned by others [25]. Factorial experimentation; in which experiments are performed for all possible combinations of the assigned levels of these factors is a good alternative. In some cases, a factor could be assigned two levels; a high level (level A) and low level (level B). Consequently; several runs of the experiment must be performed at all AB treatment combinations [26].

In case there are only two factors, and each of these factors is to be experimented at two different levels; a total four experiments $(2 \times 2=4$ runs $)$ are needed; or simply a $2^{2}$ factorial design. In general, for a number of factors, $k$, the total number of experiments is $2^{\mathrm{k}}$, where 2 refers to the number of levels for each factor (called two-level factorials). In fact, two-level factorial designs have several advantages. They require performing a relatively few runs of experiments. They can often provide a promising direction for further experimentation for quantitative variables, although they do not fully explore a wide region of the search space. In this case, however, it is important to avoid choosing these low and high values at extreme conditions but yet at the edges of normal operation. i.e., to use the minimum and maximum values that they could possibly have, otherwise they could likely be too extreme [27].

When there are many factors that we need to identify as in our case, the $2^{k}$ runs required for a full-factorial might become hard and too costly to implement. Running two-level fractionalfactorial designs (discussed later in section 3.3 ), where only a carefully chosen part of the full-factorial is performed, could allow us to estimate the main effects of the variables being addressed. In full and fractional-factorial experiments, factor activity is usually described in terms of a "main effectinteraction" model. This is one of the advantages of factorial experimentation over the one-factor-at-a-time method. In the latter method, factors are varied one at a time, while the remaining factors are held constant. This method only gives an estimate for the effect of a single factor at a fixed conditions of the rest of the factors. The factorial design, unlike the onefactor-at-a-time approach can predict estimates for such interactions.

\subsection{Mutliple Linear Regression Using Least Squares Model}

Any given problem might involve the exploration of relationships between two or more variables. Regression analysis is a statistical method useful for such types of problems [26]. It is used to model the relationship between a scalar response (or dependent variable) and one or more explanatory variables (or independent variables). Simple linear regression model is used to analyze the relationship between a dependent variable and one independent variable. When there is more than one independent variable, the linear model is termed as "Multiple Linear Regression" (MLR) model. The general problem that needs to be solved in regression analysis is to fit a straight line to a set of data points. A general probabilistic linear regression model where only one independent variable exists assume that the expected value of $y$ is a linear function of $x$ :

$$
\begin{aligned}
& \Sigma\{y\}=\beta_{0}+\beta_{1} x \\
& y=\beta_{0}+\beta_{1} x+\epsilon
\end{aligned}
$$

Where $y$ is a measured response (the independent variable), $x$ is termed as independent or explanatory variable. The parameter $\beta_{0}$ is termed as "the intercept" and the parameter $\beta_{1}$ is termed as slope parameter. $\beta_{0}, \beta_{1}$ are usually called regression coefficients. Equation (1) above assumes a linear function of the unknown parameters $\beta_{0}, \beta_{1}$. The term $\epsilon$ (called error) represents any un-modelled components of the linear model. It accounts for the failure of data to lie on the straight line. $\beta_{0}$, $\beta_{1}$ and $\epsilon$ are unknown constants that need to be estimated. The estimates of these parameters; $\hat{\beta}_{0}$ and $\hat{\beta}_{1}$ should result in a line that best fits to the data[26]. In this study; to predict the estimates the regression coefficient; the "Least Squares Method" will be used. Adopting least square method to estimate these regression coefficients of vector $x$ and vector $y$ in equation (1) for any given observation $i$; the equation could be written as follows; 


$$
\begin{aligned}
& y_{i}=b_{0}+b_{1} x_{i}+e_{i} \\
& \hat{y}_{i}=b_{0}+b_{1} x_{i}
\end{aligned}
$$

Where $b_{0}=\hat{\beta}_{0}, b_{1}=\hat{\beta}_{1}$, and $e=\hat{\epsilon}$. " $\hat{y}$ " (Y-hat) represents the predicted equation for a line of best fit in linear regression. It is used to differentiate between the predicted (or fitted) data and the observed data " $y$ ". It is also used in calculating the residuals of $y-\hat{y}$, which are the vertical differences between the observed and fitted values. The goal is to estimate the values of $b_{0}$ and $b_{1}$ from $n$ pairs of data collected, i.e.; the recorded values of both the dependent and independent variables $\left(x_{i}, y_{i}\right)$. To have good predictions, the values for the error $e_{i}$ should be very small. The least squares model is simply an optimization problem that aims to minimize the sum of all squared errors (over all $n$ values of error). Having $n$ data points $\left(x_{i}, y_{i}\right)$, means that there exist $n$ number of errors $e_{i}$, it is required to square these errors, sum them up and that is the objective function that needs to be minimized [24,27]. This could be expressed by equation (3) below;

$$
\sum_{i=1}^{n}\left(e_{i}\right)^{2}
$$

The above equations (1) \& (2) only considered the simple regression model where a dependent variable is related to only one explanatory variable. In real life practice, as well as the target of this study, there exist more than one variable that influence the dependent variable, and most of the time; these variables are mutually interacting as discussed before. These mutual dependences are taken into account by formulating a multiple regression model including more than one explanatory variable. However, in MLR, the general linear model with several explanatory variables is given by the equations (4) \& (5) $[24]$ :

$$
\begin{aligned}
y_{i} & =\beta_{1} x_{1}+\beta_{2} x_{2}+\cdots+\beta_{k} x_{k}+\epsilon_{i} \quad(i=1 . \cdots \cdot n) \\
y_{i} & =\left[x_{1}, x_{2} \cdots, x_{k}\right]\left[\begin{array}{c}
\beta_{1} \\
\beta_{2} \\
\vdots \\
\beta_{k}
\end{array}\right]+\epsilon_{i} \\
y_{i} & =\underbrace{x^{T}}_{1 \times k} \underbrace{\beta}_{k \times 1}+\epsilon_{i}
\end{aligned}
$$

And writing the last equation $n$ times over for each observation in the data

$$
\begin{gathered}
{\left[\begin{array}{l}
y_{1} \\
y_{2} \\
y_{n}
\end{array}\right]=\left[\begin{array}{cccc}
x_{1.1} & x_{1.2} & \cdots & x_{1 . k} \\
x_{2.1} & x_{2.2} & \cdots & x_{2 . k} \\
\vdots & \vdots & \ddots & \vdots \\
x_{n .1} & x_{n .2} & \cdots & x_{n . k}
\end{array}\right]\left[\begin{array}{c}
b_{1} \\
b_{2} \\
\vdots \\
b_{k}
\end{array}\right]+\left[\begin{array}{c}
e_{1} \\
e_{2} \\
\vdots \\
e_{n}
\end{array}\right]} \\
y=X b+e
\end{gathered}
$$

Where; $y=n \times 1, X=n \times 1, b=n \times 1$, and

$$
e=n \times 1
$$

Again, as with the simple least squares model, $y=b_{0}+b_{1} x$, the aim here is to minimize the sum of squares of the errors in vector $e$. Fortunately, statistical software programs could solve these optimization problems and thus provide estimates of the effects for any $2^{\mathrm{K}}$ factorial design. In this Study; to solve these least squares models described above, $\mathrm{R}$ and RStudio computer software is used.

\subsection{Fractional factorials}

In a full factorial, to investigate a system with four factors, a total of 16 experiments is needed. Most of the time, this is both time and cost prohibitive. Although $2^{4}$ factorials can give estimates to the coefficients of all main factor effects as well as two-factors, three-factors and four-factor interactions coefficients; yet the three-factor interactions and higher order interactions are too small that they are practically negligible. Fractional factorial designs allow to investigate many factors in number of fewer runs than a full factorial design. A trade-off here exists; although fewer experiments are performed in this approach yet still less information could be obtained from the system than in a full factorial. This is mainly based on the implicit assumption to ignore higher-order interaction coefficients. Therefore; when planning for an experiment, it is very important to make reasonable assumptions in order to retain the essential information of the main effects in a given system [26].

Running a half (or quarter) fraction, of the full factorial, allows to estimate the main effects as well as factor interactions at the expense of confounding these factors with higher interactions. Provided that interactions involving three or more factors are negligible, it is thus the main effects and the two-factor interactions that are mostly of practical significance. Resolution IV fractional factorial designs prevent all main effects from being biased as they avoid aliasing between the main effects and two-factor interactions. Although some of the two-factor interactions are aliased together, yet this aliasing among two-factor interactions only is an acceptable trade-off [27].

\section{PLANNING OF THE EXPERIMENT}

In order to generate all the necessary data with a lower cost and effort, planning for the experiment is important. In this section; the structure of the factorial experiment design to generate least squares estimates for all factor effects and relevant interactions for a PV system is discussed. The independent variables that can affect the experiment, and the minimum number of runs needed to obtain the most experimental information are decided. Two levels for each independent variable are defined; a high level and a low level. Values assigned for each of these levels are decided in order to achieve the objectives of the experiment in the simplest possible way. For the case study in section 5, these levels are defined to fit the conditions of a net plus energy house located in Cairo, Egypt. However, the same procedures can be followed for other case studies as well.

In the approach proposed in this study; a resolution IV $2^{4-1}$ fractional factorial design is used. The $y$ variable (the outcome of the experiment) represents the total generated electricity by a PV system. Four factors are investigated; including a single qualitative factor; that is the type of PV cells technology used; either Single-crystal Silicon (sc-Si) "Type 1" or Multicrystalline Silicon (mc-Si) "Type 2" and three quantitative 
(geometric) factors; the Area, the Tilt Angle $\beta$ (inclination from horizontal) and the Azimuth $\gamma$ (clockwise from North). Yates analysis exploits the special structure of these designs to generate least squares estimates for all factors' main effects and all relevant interactions. Each factor is assigned two levels (typically called the low and high levels). The symbols "-" and "+" represent, respectively, the lower and upper levels of the factors.

The arrangement of the experiment is thus a $2^{4-1}$, or $2^{3}$, factorial design and the data for the eight formulations where the factor levels are coded by plus (+) and minus (-) signs are shown in Table 1 below. The first three factors; the PV cells technology type, the area and the tilt angle are coded as factors A, B and C respectively. the fourth factor, the azimuth; will be created as the product of the first three factors $\mathrm{A}, \mathrm{B}$ and $\mathrm{C}$. Therefore, Factor- $\mathrm{D}$ is defined as $\mathrm{D}=\mathrm{ABC}$, and the defining relation for this subset of the factorial is expressed as shown in equation (6) below

\section{$\mathrm{I}=\mathrm{ABCD}$}

Where "I" denotes the identity column, the elements (I, ABCD) form its defining contrast subgroup (called words). According to this defining relation, no aliasing exists between main effects and two-factor interactions. The main effect of Factor- $A$ is confounded by the BCD-interaction, Factor-B with ACDinteraction, Factor- $\mathrm{C}$ with $\mathrm{ABD}$-interaction, and Factor-D with $\mathrm{ABC}$-interaction; which was initially intended. Although the two-factor interactions $\mathrm{AC}$ and $\mathrm{BD}$ are aliased together, provided that all interactions involving three or more factors are neglected, this design shall provide near estimates for all the main effects.

\subsection{PV cells technology type}

Photovoltaic cells are typically available in square sizes of around $12.5 \mathrm{~cm} \times 15 \mathrm{~cm}$. It is considered the smallest unit in a photovoltaic power system. PV cells can generally be classified as either; (1) wafer-based crystalline (single crystal and multi- crystalline silicon), (2) compound semiconductor (Thin-film), or (3) organic semiconductor. Currently crystalline silicon technologies account for more than $97 \%$ of the overall photovoltaic cell production. Single crystal silicon (also called Monocrystalline silicon) PV cells are formed with the wafers manufactured using a single crystal growth method (from pure monocrystalline silicon). Multi-crystalline silicon PV cells, are formed with multi-crystalline wafers manufactured from a cast solidification process. Although they have lower average conversion efficiency, yet they are popular because they are not expensive to produce [28]. These two types are chosen in this study as the categorical values for the Factor-A (type of PV technology used). The high and low levels for this factor are decided arbitrary; where Monocrystalline Sc. is assigned as the low level, and Polycrystalline Sc. as the high level. The surrounding topographical shading surfaces are modelled in the virtual environment using the modeling tool within the building simulation software, therefore; the shading factor was set to 1.0. The design parameters for both PV types used in the building performance simulation for the case study in section 5 are shown in Table 2 below.

\subsection{Area}

Within the frame work of the IEA SHC-Task 40 to identify the innovative solutions sets that make up NZEBs; datasets for a comprehensive collection of around 300 zero-energy buildings worldwide were acquired and analyzed $[29,30]$. In the Subtask$\mathrm{C}$, an in-depth analysis was conducted on a short list of 30 zero energy buildings, where they were classified according to the building type as either residential or non-residential. However; since this paper focuses on residential NPEBs/NZEBs, therefore; among the 30 case studies included in the Subtask-C report, only the residential buildings are taken into consideration. Table 3 shows a summary for eleven residential buildings included in the shortlist [31]. Areas for the PV system used in these case studies ranged from $33 \mathrm{~m}^{2}$ to $245 \mathrm{~m}^{2}$ (except for Plus Energy Settlement). According to the aforementioned literature; in this study, the high and low levels for the Factor$B$ are assigned as $45 \mathrm{~m}^{2}$ and $250 \mathrm{~m}^{2}$ respectively

Table 1. The eight formulations for the experiment arranged in the standard order.

\begin{tabular}{|c|c|c|c|c|c|c|c|c|c|}
\hline & \multicolumn{2}{|c|}{$\begin{array}{l}\text { PV Type } \\
\text { Factor-A }\end{array}$} & \multicolumn{2}{|c|}{$\begin{array}{c}\text { Area } \\
\text { Factor-B }\end{array}$} & \multicolumn{2}{|c|}{$\begin{array}{l}\text { Tilt angle } \\
\text { Factor-C }\end{array}$} & \multicolumn{2}{|c|}{$\begin{array}{l}\text { Azimuth } \\
\text { Factor-D }\end{array}$} & \\
\hline & - & + & - & + & - & + & - & + & \\
\hline & Type 1 & Type2 & Areal & Area2 & Angle1 & Angle2 & Azim. 1 & Azim.2 & \\
\hline Run no. & \multicolumn{8}{|c|}{ Coded Unites factors } & Outcome \\
\hline & \multicolumn{2}{|c|}{$\mathbf{A}$} & \multicolumn{2}{|c|}{$\mathbf{B}$} & \multicolumn{2}{|c|}{$\mathbf{C}$} & \multicolumn{2}{|c|}{$\mathbf{D}$} & $Y$ \\
\hline 1 & - & Type1 & - & Areal & - & Angle1 & - & Azim. 1 & $Y_{1}$ \\
\hline 2 & + & Type 2 & - & Area1 & - & Angle1 & + & Azim.2 & $Y_{2}$ \\
\hline 3 & - & Type 1 & + & Area2 & - & Angle1 & + & Azim.2 & $Y_{3}$ \\
\hline 4 & + & Type2 & + & Area2 & - & Angle1 & - & Azim. 1 & $Y_{4}$ \\
\hline 5 & - & Type1 & - & Area1 & + & Angle2 & + & Azim. 2 & $Y_{5}$ \\
\hline 6 & + & Type2 & - & Area1 & + & Angle2 & - & Azim. 1 & $Y_{6}$ \\
\hline 7 & - & Type 1 & + & Area2 & + & Angle2 & - & Azim. 1 & $Y_{7}$ \\
\hline 8 & + & Type2 & + & Area2 & + & Angle2 & + & Azim. 2 & $Y_{8}$ \\
\hline
\end{tabular}


International Journal of Engineering Research and Technology. ISSN 0974-3154 Vol.13, No.3 (2020), pp. 528-539

(C) International Research Publication House. https://dx.doi.org/10.37624/IJERT/13.3.2020.528-539

Table 2. Design parameters for the PV types used in the experiment.

\begin{tabular}{ccccccc}
\hline $\begin{array}{c}\text { Module } \\
\text { Nominal } \\
\text { Efficiency }\end{array}$ & $\begin{array}{c}\text { Nominal Cell } \\
\text { Temperature } \\
(\text { NOCT })\left({ }^{\circ} \mathrm{C}\right)\end{array}$ & $\begin{array}{c}\text { Reference } \\
\text { Irradiance for } \\
\left.\text { NOCT W/(m }{ }^{2}\right)\end{array}$ & $\begin{array}{c}\text { Temperature } \\
\text { Coefficient for Module } \\
\text { Efficiency }(1 / \mathrm{K})\end{array}$ & $\begin{array}{c}\text { Degradation } \\
\text { Factor }\end{array}$ & $\begin{array}{c}\text { Electrical } \\
\text { conversion } \\
\text { Efficiency }\end{array}$ \\
\hline $\mathbf{s c - S i}$ & 0.25 & 45 & 800 & 0.0040 & 0.99 & 0.085 \\
$\mathbf{m c - S i}$ & 0.15 & 45 & 800 & 0.0040 & 0.99 & 0.085 \\
\hline
\end{tabular}

Table 3. Summary for the residential buildings included in IEA-Task 40- subtask C report.

\begin{tabular}{ccccccc}
\hline Project & Year & Location & Latitude & Longitude & PV Technology & Area $\left(\mathbf{m}^{2}\right)$ \\
\hline Kleehaeuser & 2006 & Germany & $47^{\circ} 58^{\prime} 36.47^{\prime \prime} \mathrm{N}$ & $7^{\circ} 49^{\prime} 18.93 " \mathrm{~W}$ & $\mathrm{mc}-\mathrm{Si}$ & 202 \\
Plus Energy Settlemen & 2006 & Germany & $47^{\circ} 58^{\prime} 29.73^{\prime \prime} \mathrm{N}$ & $7^{\circ} 49^{\prime} 46.88^{\prime \prime} \mathrm{W}$ & $\mathrm{mc}-\mathrm{Si}$ & $3205^{*}$ \\
Plus Energy Houses & 2006 & Austria & $47^{\circ} 21^{\prime} 67^{\prime \prime} \mathrm{N}$ & $15^{\circ} 61^{\prime} 7^{\prime \prime} \mathrm{W}$ & $\mathrm{mc}-\mathrm{Si}$ & $40 \mathrm{~m}^{2}$ x 9 houses \\
Single family house & 2007 & Switzerland & $47^{\circ} 34^{\prime} 48^{\prime \prime} \mathrm{N}$ & $7^{\circ} 40^{\prime} 4.8^{\prime \prime} \mathrm{E}$ & - & 84 \\
Riverdale & 2008 & Canada & $53^{\circ} 20^{\prime} 24^{\prime \prime} \mathrm{N}$ & $113^{\circ} 18^{\prime} 36^{\prime \prime} \mathrm{W}$ & Sanyo & 33 \\
ÉcoTerra Home & 2008 & Canada & $45^{\circ} 17^{\prime} 60^{\prime \prime} \mathrm{N}$ & $72^{\circ} 17^{\prime} 60^{\prime \prime} \mathrm{W}$ & Amorphous Si & 45 \\
Leaf House & 2009 & Italy & $43^{\circ} 28^{\prime} 43^{\prime \prime N}$ & $13^{\circ} 04^{\prime} 03^{\prime \prime} \mathrm{E}$ & sc-Si & 150 \\
Lima & 2009 & Spain & $41^{\circ} 24^{\prime} 29^{\prime \prime} \mathrm{N}$ & $2^{\circ} 7^{\prime} 47.36^{\prime \prime} \mathrm{E}$ & $\mathrm{mc}-\mathrm{Si}$ & - \\
EnergyFlex, & 2009 & Denmark & $55^{\circ} 39^{\prime} 35^{\prime \prime} \mathrm{N}$ & $12^{\circ} 16^{\prime} 34^{\prime \prime} \mathrm{E}$ & sc-Si & 60 \\
Casa Zero energy house & 2010 & Italy & $46^{\circ} 9^{\prime} 36^{\prime \prime} \mathrm{N}$ & $13^{\circ} 12^{\prime} 60^{\prime \prime} \mathrm{E}$ & mc-Si & 110 \\
IESC & 2011 & France & $42^{\circ} 8^{\prime} 6 " \mathrm{~N}$ & $8^{\circ} 36^{\prime} 36^{\prime \prime} \mathrm{W}$ & Amorphous Si & 245 \\
\hline
\end{tabular}

* Plus Energy Settlemen consists of 60 "EnergySurplus-Houses in addition to $125 \mathrm{~m}$ long service block. Hence, the area is relatively huge.

\subsection{Azimuth and tilt angle}

Multiple studies were carried out to find the optimum tilt angle $\beta$ and the surface azimuth $\gamma$ (orientation) for solar energy applications in different areas around the world; including PV systems, and solar collectors. Jacobson and Jadhav [32] conducted a study that provides estimates of optimal tilt angles for fixed tilt solar PV panels for different countries worldwide. Data are derived from the National Renewable Energy Laboratory's PV Watts, and optimal tilt angles are calculated assuming all panels are roof mount, facing due south in Northern Hemisphere $\left(180^{\circ}\right.$ azimuth angle) or north in the Southern Hemisphere $\left(0^{\circ}\right.$ azimuth angle). The Optimal tilt angles for fixed tilt solar PV panels in Aswan in Egypt (latitude $\varphi=23.97^{\circ}$ ) was $24^{\circ}$.El-Kassaby [33] determined the optimum tilt and azimuth angles for a solar collector and suggested that using two glass covers instead of one did not affect the value of Bopt. $\left(\beta_{\text {opt }}=\varphi+3.5^{\circ}\right)$. Hussein, Ahmad and El-Ghetany [15] investigated the performance of mono-crystalline silicon type PV modules at different orientations and tilt angles in Cairo, Egypt. It was found that the maximum yearly output energy can be obtained when PV modules are facing south with a tilt angle in the range of $20-30^{\circ}$ (at a surface tilt angle equal to the local latitude), i.e. at $\beta_{\mathrm{opt}}=20-30^{\circ}$ and $\gamma_{\mathrm{opt}}=0^{\circ}$. [34] investigated the optimum tilt angle for the solar flat-plate collectors used in Helwan, Egypt. The study showed that the optimum tilt angles show a strong seasonal trend with regard to the maximum daily insolation. During months of the winter season, the maximum daily insolation is incident on a collector surface facing south with an average tilt angle $43.33^{\circ}$, whereas during the summer season, the maximum daily insolation can be received on a nearly horizontal surface.

It could be concluded from the previous literature, that the optimum tilt angle of solar systems located in Egypt follows the general rule adopted by many researchers that yearly optimum tilt angle for a solar collector facing due south (since in Northern Hemisphere, i.e. $180^{\circ}$ azimuth angle) is about ( $\varphi \pm$ 15) where $\varphi$ is the latitude of the location and plus and minus signs are used in the winter and summer respectively. In this study, dynamic thermal simulation is performed for a case study building located in Cairo $\left(30.12^{\circ} \mathrm{N}, 31.41^{\circ} \mathrm{E}\right)$. Although the aforementioned literature shows that optimum tilt angles varies over the course of the year, however, fixed tilt solar PV panels are used in this study. The two levels assigned for the Factor-C (tilt angle) are $30^{\circ}$ for the low level (equal the latitude of Cairo), and $70^{\circ}(\varphi+40$; to exhibit a wide range away from the optimum). The low and high levels assigned for the Factor$\mathrm{D}$ (azimuth) are $180^{\circ}$ and $225^{\circ}$ respectively. A summary for the assigned levels of all four parameters are shown in Table 4 below.

\section{CASE STUDY ANALYSIS}

This case study was divided into two main stages. In the first stage; A resolution IV $2^{4-1}$ fractional-factorial experimentation is used to generate least squares estimates for the main effects and relevant interactions for the four factors mentioned previously in section 4 from 8 runs only. In the second stage; the 8 remaining runs of the $2^{4}$ full-factorial are completed and the results from the two stages are compared. In both stages; The IES- VE software is used for the energy simulation 
analysis. IES-VE tools meet the following approved international standards: (1) ASHRAE 140: 2001, 2004, 2007, 2014, (2) BEST TEST, (3) CIBSE TM33 and (4) EU EN13791: July 2000. IESVE is fully validated under ASHRAE Standard 140 and have published the results for all versions of ASHRAE Standard 140; 2001, 2004, 2007 and 2014 - Heating, Cooling and Envelope [35]. The location assumed for the installation of the PV system is Cairo $\left(30.12^{\circ} \mathrm{N}, 31.41^{\circ} \mathrm{E}\right)$. ASHRAE design weather database v6.0 is used as the source for simulation weather data. Dynamic thermal simulation was performed using the ApacheSim simulation engine in IES-VE.

\subsection{First stage:}

The aim of this stage is to generate least squares estimates for the main effects and relevant interactions on the total annual generated PV electricity for all four factors. This is generated from 8 runs only (resolution IV $2^{4-1}$ fractional factorial). Table 5 below shows the arrangement of the experiments and the data for the eight formulations where the factor levels are coded by plus (+) and minus (-) signs. The total and monthly generated energy by the PV system over a typical year are shown in Table 6. The predictive model derived from these eight formulations is given by equation (7) below;

$$
y=-10.61 A+29.92 B-6.74 C+1.08 D-7.25 A B+0.28 B D
$$

\subsection{Second stage:}

The aim of this stage is to estimate all the main effects and relevant interactions using a $2^{4}$ full factorial (16 runs).Table 7 below shows the arrangement of the experiments and the data for the 16 formulations are arranged in the standard order. The corresponding order of the 8 selected runs in the first stage are also included. The predictive model derived from these eight formulations is given by equation (8) below. Results from both stages are shown in the Pareto Plot in Figure 1.

$$
\begin{aligned}
y= & -10.78 A+29.98 B-6.91 C-0.92 D-7.5 A B+1.72 A C \\
& +0.22 A D-4.79 B C-0.64 B D+0.25 C D+1.2 A B C+ \\
& 0.17 A B D-0.059 A C D+0.17 B C D-0.046 A B C D
\end{aligned}
$$

\subsection{Validation of the predictive model}

The validation process involves comparing the outcome data from the predictive model against the outcome data from dynamic thermal simulation; where these data were specifically collected for validation. For this purpose; each of the four parameters of the predictive model (PV type, area, tilt and azimuth) is assigned three different levels and dynamic thermal simulations to collect data for all possible combinations of these assigned levels were performed. The different levels assigned for each factor is presented in Table 8 below. This yields 54 different possible combinations shown in Table 9.

However; since the eight formulations 1,9,21,25,30,34,46 and 54 are used for building this predictive model, they are excluded from the validation procedures. The remaining 46 formulations were simulated to generate the data required for model validation. The first step in the validation procedure is to plot out the data in a time series with the simulated results and the model predicted results both on the same graph Figure 2 to compare them visually.

\begin{tabular}{|c|c|c|c|c|c|}
\hline & $\begin{array}{l}\text { PV Type } \\
\text { Factor-A }\end{array}$ & $\begin{array}{c}\text { Area } \\
\text { Factor-B }\end{array}$ & $\begin{array}{c}\text { Tilt angle } \\
\text { Factor-C }\end{array}$ & $\begin{array}{l}\text { Azimuth } \\
\text { Factor-D }\end{array}$ & \\
\hline Run no. & \multicolumn{4}{|c|}{ Coded Unites factors } & Outcome \\
\hline & $\mathbf{A}$ & $\mathbf{B}$ & $\mathbf{C}$ & D & $Y$ \\
\hline 1 & - Mono-crystalline Sc & -45 & $-30^{\circ}$ & $-180^{\circ}$ & 19.53 \\
\hline 2 & $+\quad$ Poly-crystalline Sc. & -45 & $-30^{\circ}$ & $+225^{\circ}$ & 11.18 \\
\hline 3 & - Mono-crystalline Sc & +250 & $-30^{\circ}$ & $+225^{\circ}$ & 103.56 \\
\hline 4 & $+\quad$ Poly-crystalline Sc. & +250 & $-30^{\circ}$ & $-180^{\circ}$ & 65.10 \\
\hline 5 & - Mono-crystalline Sc & -45 & $+70^{\circ}$ & $+225^{\circ}$ & 13.56 \\
\hline 6 & $+\quad$ Poly-crystalline Sc. & -45 & $+70^{\circ}$ & $-180^{\circ}$ & 8.45 \\
\hline 7 & - Mono-crystalline Sc & +250 & $+70^{\circ}$ & $-180^{\circ}$ & 78.20 \\
\hline 8 & $+\quad$ Poly-crystalline Sc. & +250 & $+70^{\circ}$ & $+225^{\circ}$ & 45.21 \\
\hline
\end{tabular}

Table 4. summary for the assigned levels of all four parameters.

\begin{tabular}{lcccc}
\hline System parameters & Unit & Factor & $(-)$ & $(+)$ \\
\hline $\begin{array}{l}\text { Categorical factors } \\
\text { 1. PV type (technology) }\end{array}$ & - & A & Mono-crystalline Sc. & Poly-crystalline Sc. \\
\hline $\begin{array}{l}\text { Numeric factors } \\
\text { 2. Area }\end{array}$ & $\mathrm{m}^{2}$ & $\mathrm{~B}$ & 45 & 250 \\
3. Tilt angle (inclination from horizontal) & degree & $\mathrm{D}$ & $30^{\circ}$ & $70^{\circ}$ \\
4. Azimuth (clockwise from North) & degree & $\mathrm{C}$ & $180^{\circ}$ & $225^{\circ}$ \\
\hline
\end{tabular}

Table 5. Arrangement of the experiment and the data for the eight formulations in stage 1 . 
Table 6. The total and monthly generated energy by the PV system over a typical year.

\begin{tabular}{ccccccccc}
\hline Date & Run 01 & Run 02 & Run 03 & Run 04 & Run 05 & Run 06 & Run 07 & Run 08 \\
\hline Jan & 1.5557 & 0.8372 & 7.7519 & 5.1856 & 1.2411 & 0.9211 & 8.529 & 4.137 \\
Feb & 1.5366 & 0.8441 & 7.8159 & 5.1221 & 1.1641 & 0.8327 & 7.7103 & 3.8804 \\
Mar & 1.7773 & 1.0042 & 9.2978 & 5.9243 & 1.2438 & 0.8224 & 7.6145 & 4.1459 \\
Apr & 1.7187 & 0.9994 & 9.2541 & 5.7291 & 1.1054 & 0.6318 & 5.8497 & 3.6846 \\
May & 1.604 & 0.965 & 8.935 & 5.3467 & 0.9772 & 0.4683 & 4.336 & 3.2573 \\
Jun & 1.5846 & 0.9731 & 9.0102 & 5.2819 & 0.915 & 0.3835 & 3.5512 & 3.0501 \\
Jul & 1.6465 & 1.0041 & 9.2968 & 5.4884 & 0.9736 & 0.4271 & 3.9546 & 3.2455 \\
Aug & 1.7101 & 1.0143 & 9.3912 & 5.7002 & 1.0812 & 0.5622 & 5.206 & 3.604 \\
Sep & 1.6835 & 0.9686 & 8.9688 & 5.6118 & 1.1609 & 0.7227 & 6.6919 & 3.8697 \\
Oct & 1.6681 & 0.9316 & 8.6258 & 5.5602 & 1.2582 & 0.8646 & 8.0051 & 4.1938 \\
Nov & 1.5438 & 0.8371 & 7.7509 & 5.1458 & 1.2184 & 0.8959 & 8.2958 & 4.0613 \\
Dec & 1.5019 & 0.8058 & 7.4608 & 5.0063 & 1.2245 & 0.913 & 8.4536 & 4.0816 \\
\hline Total & 19.53 & 11.18 & 103.56 & 65.10 & 13.56 & 8.45 & 78.20 & 45.21 \\
\hline
\end{tabular}

Table 7. The arrangement of the experiment and the data for the 16 formulations in Stage 2.

\begin{tabular}{|c|c|c|c|c|c|c|}
\hline \multirow{2}{*}{$\begin{array}{l}\text { Runs in the } \\
\text { full factorial }\end{array}$} & PV Type & Area & Tilt angle & Azimuth & \multirow{3}{*}{$\begin{array}{l}\text { Runs in the IV } 2^{4-1} \\
\text { fractional factorial }\end{array}$} & \multirow{2}{*}{ Outcome } \\
\hline & \multicolumn{4}{|c|}{ Coded Unit Factors } & & \\
\hline & $\mathrm{A}$ & $\mathrm{B}$ & $\mathrm{C}$ & $\mathrm{D}$ & & \\
\hline 1 & - & - & - & - & 1 & 19.53 \\
\hline 2 & + & - & - & - & & 11.79 \\
\hline 3 & - & + & - & - & & 108.50 \\
\hline 4 & + & + & - & - & 4 & 65.10 \\
\hline 5 & - & - & + & - & & 14.06 \\
\hline 6 & + & - & + & - & 6 & 8.45 \\
\hline 7 & - & + & + & - & 7 & 78.20 \\
\hline 8 & + & + & + & - & & 46.92 \\
\hline 9 & - & - & - & + & & 18.64 \\
\hline 10 & + & - & - & + & 2 & 11.19 \\
\hline 11 & - & + & - & + & 3 & 103.56 \\
\hline 12 & + & + & - & + & & 62.14 \\
\hline 13 & - & - & + & + & 5 & 13.56 \\
\hline 14 & + & - & + & + & & 8.14 \\
\hline 15 & - & + & + & + & & 75.35 \\
\hline 16 & + & + & + & + & 8 & 45.21 \\
\hline
\end{tabular}

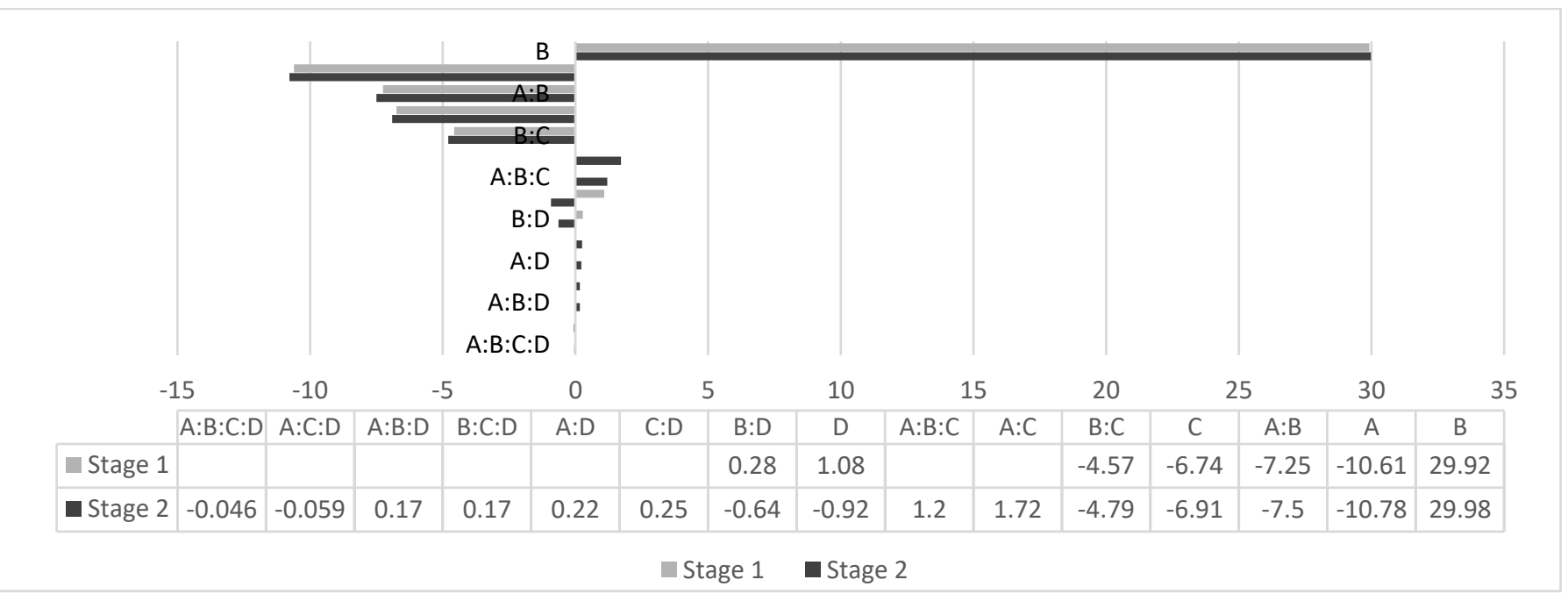

Figure 1. Pareto plot for the magnitude of the all factors and interactions effects in both stages. 
Table 8: Levels assigned for system parameters for model validation.

\begin{tabular}{lccccc}
\hline System parameters & Unit & Factor & $\mathbf{( - 1 )}$ & $\mathbf{( 0 )}$ & $\mathbf{( + 1 )}$ \\
\hline $\begin{array}{l}\text { Categorical factors } \\
\text { 1. PV type (technology) }\end{array}$ & - & A & Mono-crystalline Sc. & - & Poly-crystalline Sc. \\
\hline $\begin{array}{l}\text { Numeric factors } \\
\text { 2. Area }\end{array}$ & $\mathrm{m}^{2}$ & $\mathrm{~B}$ & & & \\
3. Tilt angle (inclination from horizontal) & degree & $\mathrm{D}$ & 45 & 147.5 & 250 \\
4. Azimuth (clockwise from North) & degree & $\mathrm{C}$ & $30^{\circ}$ & 50 & $70^{\circ}$ \\
\hline
\end{tabular}

Table 9: Different formulations to generate the data required for model validation.

\begin{tabular}{|c|c|c|c|c|c|c|c|c|c|}
\hline & PV Type & $\begin{array}{c}\text { Area } \\
\mathrm{m}^{2}\end{array}$ & $\begin{array}{c}\text { Tilt } \\
\text { degree }\end{array}$ & $\begin{array}{c}\text { Azimuth } \\
\text { degree }\end{array}$ & & PV Type & $\begin{array}{c}\text { Area } \\
\mathrm{m}^{2}\end{array}$ & $\begin{array}{c}\text { Tilt } \\
\text { degree }\end{array}$ & $\begin{array}{c}\text { Azimuth } \\
\text { degree }\end{array}$ \\
\hline 1 & sc-Si & 45 & 30 & 180 & 28 & $\mathrm{mc}-\mathrm{Si}$ & 45 & 30 & 180 \\
\hline 2 & $\mathrm{sc}-\mathrm{Si}$ & 45 & 30 & 202.5 & 29 & $\mathrm{mc}-\mathrm{Si}$ & 45 & 30 & 202.5 \\
\hline 3 & $\mathrm{sc}-\mathrm{Si}$ & 45 & 30 & 225 & 30 & $\mathrm{mc}-\mathrm{Si}$ & 45 & 30 & 225 \\
\hline 4 & $\mathrm{Sc}-\mathrm{Si}$ & 147.5 & 30 & 180 & 31 & $\mathrm{mc}-\mathrm{Si}$ & 147.5 & 30 & 180 \\
\hline 5 & $\mathrm{sc}-\mathrm{Si}$ & 147.5 & 30 & 202.5 & 32 & $\mathrm{mc}-\mathrm{Si}$ & 147.5 & 30 & 202.5 \\
\hline 6 & $\mathrm{sc}-\mathrm{Si}$ & 147.5 & 30 & 225 & 33 & $\mathrm{mc}-\mathrm{Si}$ & 147.5 & 30 & 225 \\
\hline 7 & $\mathrm{sc}-\mathrm{Si}$ & 250 & 30 & 180 & 34 & $\mathrm{mc}-\mathrm{Si}$ & 250 & 30 & 180 \\
\hline 8 & $\mathrm{sc}-\mathrm{Si}$ & 250 & 30 & 202.5 & 35 & $\mathrm{mc}-\mathrm{Si}$ & 250 & 30 & 202.5 \\
\hline 9 & $\mathrm{Sc}-\mathrm{Si}$ & 250 & 30 & 225 & 36 & $\mathrm{mc}-\mathrm{Si}$ & 250 & 30 & 225 \\
\hline 10 & $\mathrm{Sc}-\mathrm{Si}$ & 45 & 50 & 180 & 37 & $\mathrm{mc}-\mathrm{Si}$ & 45 & 50 & 180 \\
\hline 11 & $\mathrm{sc}-\mathrm{Si}$ & 45 & 50 & 202.5 & 38 & $\mathrm{mc}-\mathrm{Si}$ & 45 & 50 & 202.5 \\
\hline 12 & $\mathrm{sc}-\mathrm{Si}$ & 45 & 50 & 225 & 39 & $\mathrm{mc}-\mathrm{Si}$ & 45 & 50 & 225 \\
\hline 13 & $\mathrm{sc}-\mathrm{Si}$ & 147.5 & 50 & 180 & 40 & $\mathrm{mc}-\mathrm{Si}$ & 147.5 & 50 & 180 \\
\hline 14 & $\mathrm{sc}-\mathrm{Si}$ & 147.5 & 50 & 202.5 & 41 & $\mathrm{mc}-\mathrm{Si}$ & 147.5 & 50 & 202.5 \\
\hline 15 & $\mathrm{Sc}-\mathrm{Si}$ & 147.5 & 50 & 225 & 42 & $\mathrm{mc}-\mathrm{Si}$ & 147.5 & 50 & 225 \\
\hline 16 & $\mathrm{sc}-\mathrm{Si}$ & 250 & 50 & 180 & 43 & mc-Si & 250 & 50 & 180 \\
\hline 17 & $\mathrm{sc}-\mathrm{Si}$ & 250 & 50 & 202.5 & 44 & $\mathrm{mc}-\mathrm{Si}$ & 250 & 50 & 202.5 \\
\hline 18 & $\mathrm{sc}-\mathrm{Si}$ & 250 & 50 & 225 & 45 & $\mathrm{mc}-\mathrm{Si}$ & 250 & 50 & 225 \\
\hline 19 & $\mathrm{sc}-\mathrm{Si}$ & 45 & 70 & 180 & 46 & $\mathrm{mc}-\mathrm{Si}$ & 45 & 70 & 180 \\
\hline 20 & $\mathrm{sc}-\mathrm{Si}$ & 45 & 70 & 202.5 & 47 & $\mathrm{mc}-\mathrm{Si}$ & 45 & 70 & 202.5 \\
\hline 21 & sc-Si & 45 & 70 & 225 & 48 & $\mathrm{mc}-\mathrm{Si}$ & 45 & 70 & 225 \\
\hline 22 & $\mathrm{Sc}-\mathrm{Si}$ & 147.5 & 70 & 180 & 49 & $\mathrm{mc}-\mathrm{Si}$ & 147.5 & 70 & 180 \\
\hline 23 & $\mathrm{sc}-\mathrm{Si}$ & 147.5 & 70 & 202.5 & 50 & $\mathrm{mc}-\mathrm{Si}$ & 147.5 & 70 & 202.5 \\
\hline 24 & $\mathrm{Sc}-\mathrm{Si}$ & 147.5 & 70 & 225 & 51 & $\mathrm{mc}-\mathrm{Si}$ & 147.5 & 70 & 225 \\
\hline 25 & $\mathrm{sc}-\mathrm{Si}$ & 250 & 70 & 180 & 52 & mc-Si & 250 & 70 & 180 \\
\hline 26 & $\mathrm{sc}-\mathrm{Si}$ & 250 & 70 & 202.5 & 53 & mc-Si & 250 & 70 & 202.5 \\
\hline 27 & $\mathrm{sc}-\mathrm{Si}$ & 250 & 70 & 225 & 54 & $\mathrm{mc}-\mathrm{Si}$ & 250 & 70 & 225 \\
\hline
\end{tabular}

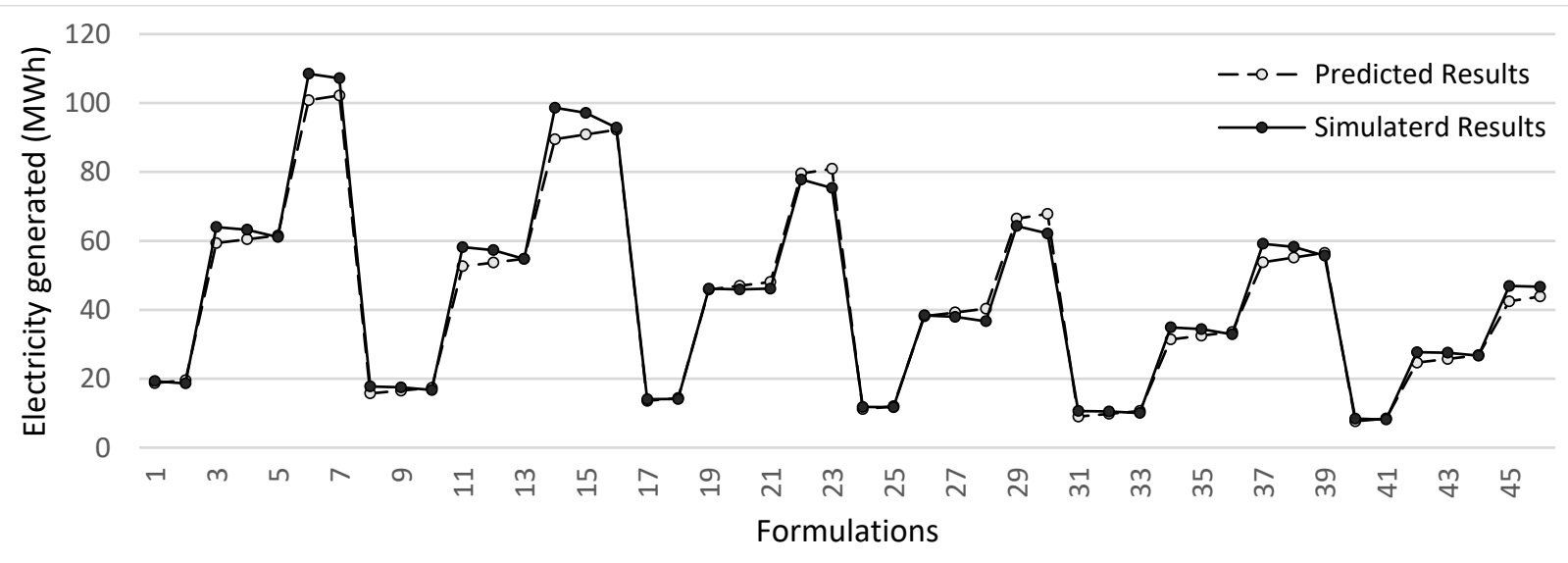

Figure 2: Time series plot for predicted and simulated results. 
The second step is to statistically validate the prediction model. A common approach to evaluate the adequacy of the model is to regress predicted results vs. simulated results and to test the slope of the regression line against one and the intercept against zero [36]. If the model gives good estimates; the regression will lead to a $45^{\circ}$ line passing thorough the origin. This could be evaluated by testing if the intercept is not significantly different from zero and the slope is not significantly different from one, either separately using Student t-tests, or simultaneously using the F-test [37,38]. However; in this study, two-tail Student ttests with 0.05 Type I error rate are used to compare regression line against 1:1 line. A scatter plot was used to plot the data (Figure 3) and the summary for the output of regression analysis is shown Table $\mathbf{1 0 .}$

Table 10: Output summary of the regression analysis

\begin{tabular}{lccc}
\hline \multicolumn{4}{l}{ Regression Statistics } \\
\hline Multiple R & 0.99454 & \multicolumn{3}{l}{ Adjusted R Square } & 0.9889 \\
R Square & 0.98911 & Standard Error & 2.9774 \\
\hline \multicolumn{5}{c}{ Coefficients } & S.E. & t Stat \\
\hline The intercept (a) & -0.2106 & 0.8285 & -0.2541 \\
The slope (b) & 1.0308 & 0.0163 & 63.2302
\end{tabular}

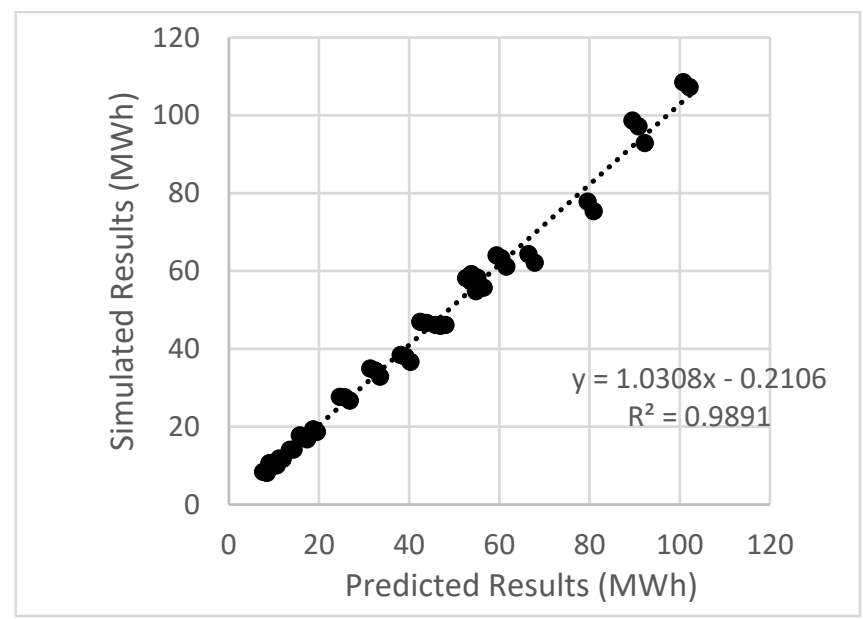

Figure 3: Scatter plot for predicted and simulated results

The null hypothesis that the intercept coefficient is not significantly different from zero is tested with $44(n-2)$ degrees of freedom by the Student t-test with $\alpha=0.05$. The value of $t$ for the intercept coefficient is

$$
\frac{-0.2106-0}{0.8285}=-0.2542
$$

This case is not significantly different from zero. Similarly; The null hypothesis that the slope coefficient is not significantly different from zero is tested and the value of $t$ for the slope coefficient is

$$
\frac{1.0308-0}{0.0163}=63.2302
$$

The null hypothesis is rejected and this $t$ value indicates a strong positive linear relationship. The null hypothesis that the slope coefficient is not significantly different from unity is tested and the value of $t$ for the slope coefficient is

$$
\frac{1.0308-1}{0.0163}=1.8895
$$

This case is not significantly different from 1 . The coefficient of determination ( $\mathrm{R}$ Square) is 0.9891 , which indicates that high proportion of the variance in the dependent variable is predictable from the independent variable.

\section{RESULTS AND DISCUSSION}

In this study, a methodology to investigate how design variations of a set of parameters for a photovoltaic system can significantly affect overall performance in few number of runs was proposed. This method was tested on a case study in Cairo, Egypt for verification. Results from the case study analysis are shown in Figure 1, where the factors were organized according to the magnitude of the factor effect (whether this effect works in favor of or against the performance of PV system). Results in the two stages show that by using IV $2^{4-1}$ fractional factorial design good estimates for the main effects can be obtained, where the aliasing between the main effects and two-factor interactions was avoided. Only the main effect of Factor-D was slightly deviated from its real magnitude (1.08 and not -0.92) since the result was confounded with the $\mathrm{ABC}$-interaction (1.2). The two-factor interactions $\mathrm{AC}$ and $\mathrm{BD}$ were also confounded with each. However; these aliasing was intentional, and these minor deviations from the full-factorial design results are an acceptable trade-off for doing half the amount of experiments.

Generally, it could be deduced that the magnitude of the Area effect (Factor-B) exceeds all other factor effects. Results also show that the type of the PV technology used (and thus their nominal efficiency) has a big influence greater even than that of the tilt angle. The two factor interactions between these three factors proved also to have a relatively high impact. Results show that Factor-D (the azimuth) within the limits used in these experiments has the least effect on the overall generated electricity. Predictions form the model proposed in this study were tested against data collected from dynamic thermal simulation using statistical hypothesis testing to assess the validity of a model. The null hypothesis that the regression line for both predicted vs simulated results is not significantly different from 1:1 line is not rejected and the model is valid under 0.05 Type I error rate. However; all these conclusions will need further verification, especially with regard to the assigned high and low level values. Further research work should extend to include more factors as well as different ranges of possibilities. It is also of a great benefit to validate the conclusions drawn from this study against measured data obtained from a DAS system used to monitor real installed PV systems so as to make sure that the results drawn from the building performance simulations are near enough to the recorded empirical data. 


\section{REFERENCES}

[1] Torcellini, P.; Pless, S.; Deru, M.; Crawley, D. Zero energy buildings: a critical look at the definition; National Renewable Energy Lab.(NREL), Golden, CO (United States): 2006.

[2] Mohamed, A.; Hasan, A.; Sirén, K. Fulfillment of netzero energy building (NZEB) with four metrics in a single family house with different heating alternatives. Applied Energy 2014, 114, 385-399.

[3] Lehr, U.; Banning, M.; Hegazi, A.; Youssef, A. The Socio-Economic impacts of Renewable Energy and Energy Efficiency in Egypt-Local Value and; RCREEE: 2017.

[4] IRENA. Renewable Energy in the Arab Region. Overview of Developments. IRENA: 2016.

[5] Sartori, I.; Napolitano, A.; Voss, K. Net zero energy buildings: A consistent definition framework. Energy and buildings 2012, 48, 220-232.

[6] RCREEE, R.C.f.R.E.a.E.E. Arab Future Energy Index ${ }^{\mathrm{TM}}(A F E X)$, Renewable Energy 2015; 2015.

[7] Dhimish, M.; Silvestre, S. Estimating the impact of azimuth-angle variations on photovoltaic annual energy production. Clean Energy 2019, 3, 47-58.

[8] Yan, R.; Saha, T.K.; Meredith, P.; Goodwin, S. Analysis of yearlong performance of differently tilted photovoltaic systems in Brisbane, Australia. Energy Conversion and Management 2013, 74, 102-108, doi:https://doi.org/10.1016/j.enconman.2013.05.007.

[9] Ismail, M.S.; Moghavvemi, M.; Mahlia, T.M.I. Design of an optimized photovoltaic and microturbine hybrid power system for a remote small community: Case study of Palestine. Energy Conversion and Management 2013, 75, 271-281, doi:https://doi.org/10.1016/j.enconman.2013.06.019.

[10] Jafarkazemi, F.; Saadabadi, S.A. Optimum tilt angle and orientation of solar surfaces in Abu Dhabi, UAE. Renewable Energy 2013, 56, 44-49, doi:https://doi.org/10.1016/j.renene.2012.10.036.

[11] Bakirci, K. General models for optimum tilt angles of solar panels: Turkey case study. Renewable and Sustainable Energy Reviews 2012, 16, 6149-6159, doi:https://doi.org/10.1016/j.rser.2012.07.009.

[12] Asowata, O.; Swart, J.; Pienaar, C. Optimum Tilt Angles for Photovoltaic Panels during Winter Months in the Vaal Triangle, South Africa. Smart Grid and Renewable Energy 2012, Vol.03No.02, 7, doi:10.4236/sgre.2012.32017.

[13] Wada, H.; Yamamoto, F.; Ueta, K.; Yamaguchi, T. Generation characteristics of $100 \mathrm{~kW}$ PV system with various tilt angle and direction arrays. Solar Energy Materials and Solar Cells 2011, 95, 382-385, doi:https://doi.org/10.1016/j.solmat.2010.04.016.

[14] Chang, Y.-P. Optimal the tilt angles for photovoltaic modules using PSO method with nonlinear timevarying evolution. Energy 2010, 35, 1954-1963, doi:https://doi.org/10.1016/j.energy.2010.01.010.
[15] Hussein, H.; Ahmad, G.; El-Ghetany, H. Performance evaluation of photovoltaic modules at different tilt angles and orientations. Energy conversion and management 2004, 45, 2441-2452.

[16] Hafez, A.Z.; Soliman, A.; El-Metwally, K.A.; Ismail, I.M. Tilt and azimuth angles in solar energy applications - A review. Renewable and Sustainable Energy Reviews 2017, 77, 147-168, doi:https://doi.org/10.1016/j.rser.2017.03.131.

[17] Le, N.T.; Benjapolakul, W. Evaluation of contribution of PV array and inverter configurations to rooftop PV system energy yield using machine learning techniques. Energies 2019, 12, 3158.

[18] Mouatasim, A.E.; Darmane, Y. Regression analysis of a photovoltaic (PV) system in FPO. In Proceedings of AIP Conference Proceedings; p. 020008.

[19] Malvoni, M.; Leggieri, A.; Maggiotto, G.; Congedo, P.M.; De Giorgi, M.G. Long term performance, losses and efficiency analysis of a $960 \mathrm{kWP}$ photovoltaic system in the Mediterranean climate. Energy Conversion and Management 2017, 145, 169-181, doi:https://doi.org/10.1016/j.enconman.2017.04.075.

[20] Di Piazza, M.C.; Vitale, G. Parameter Identification for Photovoltaic Source Models. In Photovoltaic Sources: Modeling and Emulation, Springer London: London, 2013; 10.1007/978-1-4471-4378-9_4pp. 83129.

[21] Di Piazza, M.C.; Ragusa, A.; Vitale, G. Identification of photovoltaic array model parameters by robust linear regression methods. In Proceedings of International Conference on Renewable Energies and Power Quality (ICREPQ'09).

[22] Liu, Q.; Ryu, Y.; Gao, W.; Ruan, Y. Field study and sensitive analysis of PV system by multiple regression method. Journal of Asian Architecture and Building Engineering 2004, 3, 247-252.

[23] Devore, J.L.; Farnum, N.R.; Doi, J.A. Applied Statistics for Engineers and Scientists; Cengage Learning: 2013.

[24] Dunn, K. Process improvement using data. 2019.

[25] Box, J.F. R.A. Fisher and the Design of Experiments, 1922-1926. The American Statistician 1980, 34, 1-7, doi:10.1080/00031305.1980.10482701.

[26] Montgomery, D.C.; Runger, G.C. Applied statistics and probability for engineers; John Wiley \& Sons: 2010.

[27] Box, G.E.P.; Hunter, J.S.; Hunter, W.G. Statistics for experimenters: design, innovation, and discovery; Wiley-Interscience: 2005.

[28] IEA-PVPS. Trends 2018 in photovoltaic applications: Survey report of selected IEA countries between 1992 and 2017, ; Report IEA PVPS T1-34:2018; 2018.

[29] IEA Solar Heating \& Cooling Technology Collaboration Programme. SHC Task 40 Net Zero Energy Solar Buildings. Availabe online: http://task40.iea-shc.org/publications (accessed on 25 Feb). 
[30] Musall, E. Net Zero Energy Buildings - worldwide. Availabe online: https://batchgeo.com/map/net-zeroenergy-buildings (accessed on $25 \mathrm{Feb}$ ).

[31] Garde, F.; Donn, M. Solution sets and net zero energy buildings: A review of $30 \mathrm{Net}$ ZEBs case studies worldwide; 2014.

[32] Jacobson, M.Z;; Jadhav, V. World estimates of PV optimal tilt angles and ratios of sunlight incident upon tilted and tracked PV panels relative to horizontal panels. Solar Energy 2018, 169, 55-66, doi:https://doi.org/10.1016/j.solener.2018.04.030.

[33] El-Kassaby, M.M. Monthly and daily optimum tilt angle for south facing solar collectors; theoretical model, experimental and empirical correlations. Solar \& Wind Technology 1988, 5, 589-596, doi:https://doi.org/10.1016/0741-983X(88)90054-9.

[34] Elminir, H.K.; Ghitas, A.E.; El-Hussainy, F.; Hamid, R.; Beheary, M.; Abdel-Moneim, K.M. Optimum solar flat-plate collector slope: case study for Helwan,
Egypt. Energy Conversion and Management 2006, 47, 624-637.

[35] IESVE. software-validation. Availabe online: https://www.iesve.com/software/software-validation (accessed on 19.06).

[36] Piñeiro, G.; Perelman, S.; Guerschman, J.P.; Paruelo, J.M. How to evaluate models: Observed vs. predicted or predicted vs. observed? Ecological Modelling 2008 216 , 316-322, doi:https://doi.org/10.1016/j.ecolmodel.2008.05.006.

[37] Bellocchi, G.; Rivington, M.; Donatelli, M.; Matthews, K. Validation of Biophysical Models: Issues and Methodologies. In Sustainable Agriculture Volume 2, Lichtfouse, E., Hamelin, M., Navarrete, M., Debaeke, P., Eds. Springer Netherlands: Dordrecht, 2011; 10.1007/978-94-007-0394-0_26pp. 577-603.

[38] Dent, J.B. Systems Simulation in Agriculture; Springer Netherlands: 2012. 